\title{
Human papillomavirus-associated oral intraepithelial neoplasia
}

\author{
Sook-Bin Woo ${ }^{1,2,3}$, Emma C Cashman ${ }^{4,5}$ and Mark A Lerman ${ }^{1,2,3}$ \\ ${ }^{1}$ Harvard School of Dental Medicine, Boston, MA, USA; ${ }^{2}$ Division of Oral Medicine and Dentistry, \\ Brigham and Women's Hospital, Boston, MA, USA; ${ }^{3}$ Strata Pathology Services, Cambridge, MA, USA; \\ ${ }^{4}$ Dana Farber Cancer Institute, Boston, MA, USA and ${ }^{5}$ Harvard Medical School, Boston, MA, USA
}

\begin{abstract}
This study evaluated an unusual subset of oral epithelial dysplasia for the presence of transcriptionally active high-risk HPV subtypes and to further characterize the histological criteria for this condition. There were 20 cases diagnosed as epithelial dysplasia with marked apoptosis of the anterior oral cavity. Clinical and followup data were collected and histopathological features were documented. Immunoperoxidase studies were performed for p16 and in situ hybridization studies were performed for low- and high-risk HPV sub-types. Gender- and site-matched controls of conventional moderate-to-severe oral epithelial dysplasia were similarly evaluated using immunoperoxidase studies for p16 and in situ hybridization; the number of apoptotic cells for study and control cases was counted at two different tissue sites. There were 17 men and 3 women with a median age of $\mathbf{5 6}$ years. Seventeen lesions were described as white and five were described as rough or papillary. Thirteen were located on the lateral or ventral tongue, some extending onto the floor of the mouth. Epithelial hyperplasia with marked karyorrhexis and apoptosis were present in all the cases, along with features of conventional oral epithelial dysplasia. A statistically significant number of apoptotic cells were identified in the study cases when compared with controls $(P>0.0001)$. Twenty cases were positive for high-risk HPV by in situ hybridization and all 19 nineteen cases evaluated for p16 demonstrated overexpression. Two patients were diagnosed with squamous cell carcinomas and one patient developed recurrent disease. We report a subset of oral epithelial dysplasia that occurs mostly in adult men on the ventral or lateral tongue and is positive for high-risk HPV and for p16. We propose use of the term 'HPV-associated Oral Intraepithelial Neoplasia' to characterize these lesions of the oral cavity for consistency in nomenclature with HPV-associated lesions of the lower anogenital tract. One case recurred and one developed invasive cancer.

Modern Pathology (2013) 26, 1288-1297; doi:10.1038/modpathol.2013.70; published online 19 April 2013
\end{abstract}

Keywords: HPV apoptotic oral epithelial dysplasia; koilocytic dysplasia

In the United States, smoking frequency has decreased by $16 \%$ and the overall number of cases of cancer of the oral cavity and pharynx has fallen by $18 \%$ since $1975 .{ }^{1}$ However, rates of cancers of the oral tongue, base of tongue, and palatine tonsils have continued to rise by $2-4 \%$ among younger men. ${ }^{2,3}$ This may, in part, be explained by the increased prevalence of a subset of oropharyngeal carcinoma associated with human papillomavirus (HPV), mostly HPV-16. ${ }^{4-7}$ Importantly, p16 overexpression is noted in almost all HPV-associated head and neck cancers and indicates that the virus is transcriptionally active. Patients with HPV-positive,

Correspondence: Dr MA Lerman, DMD, MMSc Division of Oral Medicine and Dentistry, Brigham and Women's Hospital, One Brigham Circle, Suite 3-028, Boston, MA 02120, USA.

E-mail: mark_lerman@hsdm.harvard.edu

Received 26 October 2012; revised 17 February 2013; accepted 19 February 2013; published online 19 April 2013 p16-positive oropharyngeal carcinomas are slightly younger than those with tumors not associated with HPV and show improved survival. ${ }^{8,9}$ It is generally believed that HPV has only a minor role in squamous cell carcinoma of the anterior oral cavity, because it has been identified in only $2.9-5.9 \%$ of cases and the behavior of these tumors has not been well characterized. ${ }^{10,11}$

Almost all squamous cell carcinomas of the oral cavity arise from oral epithelial dysplasia. Although a recent meta-analysis calculated the prevalence of HPV-16 and/or HPV-18 in oral epithelial dysplasias to be $25 \%$, these studies only identified the presence of HPV without investigating the expression of p16. ${ }^{12}$ The purpose of this study is to evaluate a subset of oral epithelial dysplasias for the presence of transcriptionally active high-risk HPV subtypes and to further characterize the histological criteria for this condition. 


\section{Materials and methods}

Cases diagnosed as epithelial dysplasia with marked apoptosis were identified in a 4-year period from September 2008 through August 2012 from the archives of Strata Pathology Services, the surgical pathology laboratory affiliated with the Harvard School of Dental Medicine in Boston, MA, USA. This unusual pattern of dysplasia is distinguished from conventional oral epithelial dysplasia by an exceptionally large number of apoptotic cells. Only cases located in the anterior oral cavity, that is, the oral mucosa anterior to the anterior tonsillar pillar (palatoglossal arch) and the circumvallate papillae of the tongue, were included.

All clinicians were contacted for clinical and follow-up data and histopathological features seen on routine hematoxylin and eosin staining were documented. Immunoperoxidase studies were performed for p16 and in situ hybridization studies were performed for low- and high-risk HPV sub-types. The primary antibody for p16 was a mouse monoclonal antibody clone E6H4TM directed against human P16INK4a and a standard twostep immunohistochemical staining procedure was used for formalin-fixed, paraffin-embedded tissue using horseradish peroxidase and goat anti-mouse antibody (CINtecTM Histology Kit, MTM Laboratories, Westborough, MA, USA). In situ hybridization studies were performed using a cocktail of biotinylated probes against low-risk HPV genotypes 6 and 11 and high-risk HPV genotypes 16, 18, 31, 33, $35,39,45,51,52,56,58$, and 66 on the Ventana Benchmark XT automated platform (Ventana Medical Systems, Tucson, AZ, USA).

Each study was graded as weak, moderate, or strong as follows:

(a) for p16: thickness of epithelium (excluding keratin) exhibiting a continuous band of nuclear and cytoplasmic staining:

$1+:<1 / 3$

$2+: 1 / 3-2 / 3$

$3+:>2 / 3$; and

Non-continuous staining was considered negative.

(b) for in situ hybridization:

$1+$ : cells with punctate nuclear staining consistent with integrated DNA involvement;

$2+$ : foci with integrated DNA involvement and/or diffuse staining consistent with episomal DNA involvement; and

$3+$ : continuous band of cells with integrated and/ or episomal DNA involvement.

Gender- and site-matched controls of conventional moderate-to-severe (high-grade) oral epithelial dysplasia, using well-accepted criteria, were selected to compare histopathological features and were evaluated using immunoperoxidase studies for p16 and in situ hybridization for low- and high-risk HPV. ${ }^{13,14}$ The number of apoptotic cells for study and control cases was counted at two different tissue sites at a magnification of $\times 600$. The means of the two observations obtained from each case were used in a Wilcoxon's rank-sum test to compare the median number of apoptotic cells among samples that displayed HPV-associated dysplasia versus those that displayed conventional oral epithelial dysplasia. All cases were reviewed by two oral and maxillofacial pathologists.

\section{Results}

Clinical data are presented in Table 1 . There were 17 men and 3 women with a median age of 56 years (range 41-71). Sixty-five percent smoked cigarettes, and one patient each smoked cigars and used smokeless tobacco. Seventeen of the 20 lesions were described as white lesions or leukoplakias and 5 were described as rough, corrugated, verrucous, or papillary. Thirteen were located on the lateral or ventral tongue (in three cases, extending onto the floor of the mouth), four on the buccal mucosa, one exclusively on the floor of mouth, and two on the gingiva/retromolar pad. Eleven cases were $\leq 1 \mathrm{~cm}$ in greatest dimension and seven were $>1 \mathrm{~cm}$ (Figure 1). One patient (case no.13) had a history of Hodgkin lymphoma; none of the patients were known to be infected with HIV.

The histopathological features were as follows:

- Brightly eosinophilic compact parakeratosis in 11 cases (Figure 2a), mixed para- and ortho-keratosis in 6 , and primarily hyperorthokeratosis in 3,1 of which was from a normally orthokeratotic site, the retromolar pad.

- Epithelial hyperplasia with marked karyorrhexis and apoptosis present throughout the epithelium (Figures 2a-d); this is the most characteristic feature of these lesions and distinguishes these lesions from the conventional oral epithelial dysplasia. A continuum of the process of apoptosis is seen beginning with karyorrhexis within keratinocytes with the usual pale eosinophilic cytoplasm ending with a brightly eosinophilic, degenerated, and anucleate cell (Figure 2d).

- Surrounding cells with features of conventional dysplasia such as cells with increased nucleus:cytoplasm ratio, hyperchromatism, and cellular and nuclear pleomorphism; of note, $>2 / 3$ of the epithelium was involved in all the cases (Figures 2c and d).

- Scattered koilocytes were noted in all the cases, although only in small numbers and only focally (Figure 3).

All 20 cases exhibited the features as described above (Table 2). In addition, cases from the ventral/ lateral tongue (case nos.3 and 14) and buccal mucosa (case nos.15 and 18) had papillary, verrucous, or corrugated surfaces (Figure 4). All cases evaluated with p16 showed strong and continuous $3+$ nuclear and cytoplasmic staining (Figure 5a). 
Table 1 Clinical data

\begin{tabular}{|c|c|c|c|c|c|}
\hline Case & Age & Sex & Site & Tobacco usage & Medications \\
\hline 1 & 51 & $\mathrm{M}$ & $\begin{array}{l}\text { Right ventral tongue/FOM; leukoplakia } \\
0.5 \mathrm{~cm}\end{array}$ & Cigarettes & None \\
\hline 2 & 60 & M & $\begin{array}{l}\text { Right lateral tongue; recurrent white } \\
\text { plaque, } 1 \mathrm{~cm}\end{array}$ & None & $\begin{array}{l}\text { Glipizide, hydrochlorothiazide, lisinopril, } \\
\text { simvastatin, tramadol }\end{array}$ \\
\hline 3 & 43 & M & $\begin{array}{l}\text { Ventral/lateral tongue; rough, white, } \\
\text { raised, } 0.5 \times 0.5 \mathrm{~cm}^{2}\end{array}$ & Cigarettes & Buproprion, venlafaxine \\
\hline 4 & 45 & $\mathrm{~F}$ & Right ventral tongue; white, $0.5 \mathrm{~cm}$ & Smokeless tobacco & Clonazepam, paroxetine \\
\hline 5 & 55 & $\mathrm{~F}$ & Right buccal mucosa; $1 \mathrm{~cm}$, white, raised & Cigarettes & Atenolol, levothyroxine \\
\hline 6 & 57 & M & $\begin{array}{l}\text { Left ventral tongue/FOM; white, raised } \\
\text { plaque, } 2 \mathrm{~cm}\end{array}$ & Cigarettes & Aspirin, folic acid, levothyroxine \\
\hline 7 & 46 & M & Left retromolar pad; white plaque, $1.5 \mathrm{~cm}$ & Cigars & None \\
\hline 8 & 70 & M & Ventral/lateral tongue; leukoplakia, $1.5 \mathrm{~cm}$ & Cigarettes & $\begin{array}{l}\text { Albuterol, aspirin, diltiazem, dutasteride, } \\
\text { famotidine, flecainide, folic acid, } \\
\text { montelukast, pravastatin, tamsulosin, } \\
\text { thiamine, valsartan, warfarin }\end{array}$ \\
\hline 9 & 59 & M & $\begin{array}{l}\text { Anterior ventral tongue; white and } \\
\text { papillary, } 0.3 \mathrm{~cm} \text {, present } 2 \text { years }\end{array}$ & None & Aspirin, atorvastatin, metoprolol \\
\hline 10 & 41 & M & $\begin{array}{l}\text { Ventral tongue, raised } 0.2 \mathrm{~cm} \mathrm{~mm} \\
\text { leukoplakia }\end{array}$ & 23 pack years & $\begin{array}{l}\text { Amoxicillin, hydrocodone/acetaminophen, } \\
\text { esomeprazole, }\end{array}$ \\
\hline 11 & 69 & M & Floor of mouth & $1 \mathrm{PPD}$ & $\begin{array}{l}\text { Doxazosin, dutasteride, solifenacin, } \\
\text { tamsulosin }\end{array}$ \\
\hline 12 & 48 & $\mathrm{M}$ & Ventral tongue, white & 2 PPD & None \\
\hline 13 & 46 & M & Right lateral tongue, white tissue, $2 \mathrm{~cm}$ & Does not smoke & Gabapentin \\
\hline 14 & 56 & $\mathrm{M}$ & Left ventral tongue, $4 \mathrm{~cm}$ white, corrugated & $1 \mathrm{PPD} \times 40$ years & None \\
\hline 15 & 62 & $\mathrm{M}$ & $\begin{array}{l}\text { Right buccal mucosa, } 2.5 \mathrm{~cm} \text { verrucous } \\
\text { leukoplakia }\end{array}$ & $1-2 \mathrm{PPD}$ & $\begin{array}{l}\text { Atenolol, atorvastatin, furosemide, } \\
\text { hydrocodone/acetaminophen, pantoprazole }\end{array}$ \\
\hline 16 & 71 & M & Right ventral tongue, White lesion, $1 \mathrm{~cm}$ & Does not smoke & $\begin{array}{l}\text { Aspirin, atorvastatin, cyclobenzaprine, } \\
\text { diclofenac, fish oil, fluticasone, } \\
\text { levothyroxine, lisinopril, misoprostol }\end{array}$ \\
\hline 17 & 56 & $\mathrm{M}$ & Right buccal mucosa, erythroplakic, $1 \mathrm{~cm}$ & Unknown & Unknown \\
\hline 18 & 62 & M & $\begin{array}{l}\text { Left buccal mucosa, red/white corrugated } \\
\text { lesion, }<1 \mathrm{~cm}\end{array}$ & 2 PPD & Aspirin, sertraline \\
\hline 19 & 55 & $\mathrm{~F}$ & $0.6 \mathrm{~cm}$ gingival leukoplakia & 1/3 PPD & Levothyroxine, omeprazole \\
\hline 20 & 62 & M & $\begin{array}{l}\text { Tongue, FOM, and mandibular mucosa, } \\
<1.3 \mathrm{~cm}\end{array}$ & 1/4 PPD & Lisinopril \\
\hline
\end{tabular}

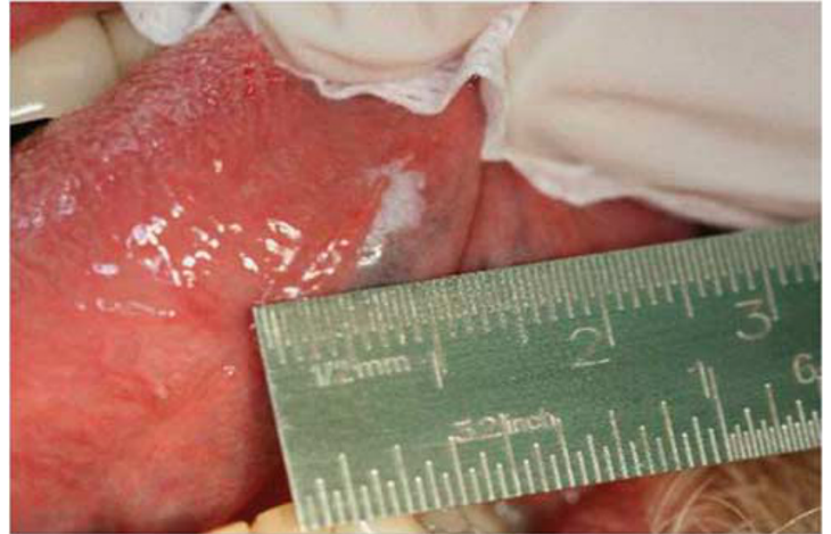

Figure 1 Case no. 4: sharply demarcated leukoplakia of the right ventral tongue. Courtesy of Dr Craig Cohen, private practice, West Lebanon, NH.

All cases evaluated by in situ hybridization for highrisk HPV were positive and 15 cases showed $2+$ or $3+$ positivity (Figure 5b). None of the cases showed positivity for low-risk HPV. In all the cases evaluated for p16, positivity stopped abruptly at the border between dysplastic and non-dysplastic epithelium, and the corresponding in situ hybridization studies for high-risk HPV demonstrated the same pattern (Figures 5a and b).
The mean number of apoptotic cells in HPV-associated cases was 19.3 (median 18; range 6-40); the mean number of apoptotic cells in controls was 1.8 (median 1; range 0-7) (Table 3). This analysis demonstrated a statistically significant difference between the medians of the two groups with a $P$-value $<0.0001$. The control cases of conventional oral epithelial dysplasia were negative for p16 and for both low- and high-risk HPV by in situ hybridization.

Seventeen of the 20 cases had positive margins. There were 12 cases with follow-up (median 8.5 months, range 1-46 months), of which 11 had positive margins (Table 2). Seven cases underwent one or more excisions or were scheduled for future excisions at the time of publication. Of the cases with follow-up and positive margins, three cases $(27 \%)$ with positive margins showed progression of residual disease (case nos. 8, 13, and 18). An additional case was submitted as recurrent but clear margins in the previous excision could not be confirmed; the patient was then lost to follow-up (case no. 2).

Two of the patients with follow-up (17\%) developed adverse outcomes, including recurrence or development of squamous cell carcinoma. One patient (case no. 8) demonstrated involvement of 


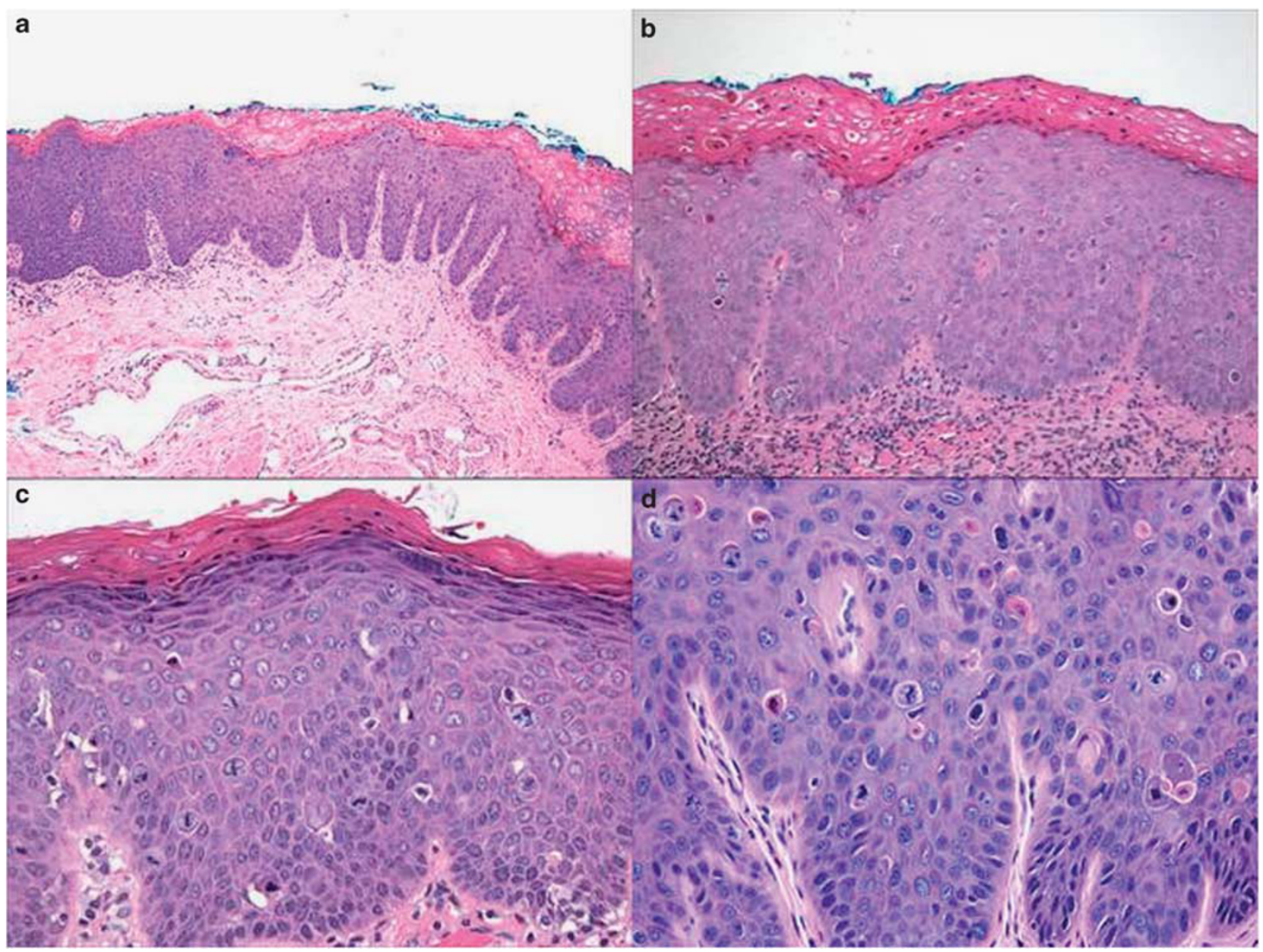

Figure 2 (a) Case no. 9: epithelial hyperplasia with eosinophilic parakeratin (hematoxylin and eosin, magnification $\times 100)$; (b) Case no.4: eosinophilic dense, compact parakeratin with 'mitosoid' figures and apoptotic cells (hematoxylin and eosin, magnification $\times 200$ ); (c) Case no. 5: parakeratosis, karyorrhexis, and maturation disarray (hematoxylin and eosin, magnification $\times 400$ ); and (d) Case no. 9: marked karyorrhexis and varying stages of apoptosis (hematoxylin and eosin, magnification $\times 400$ ).

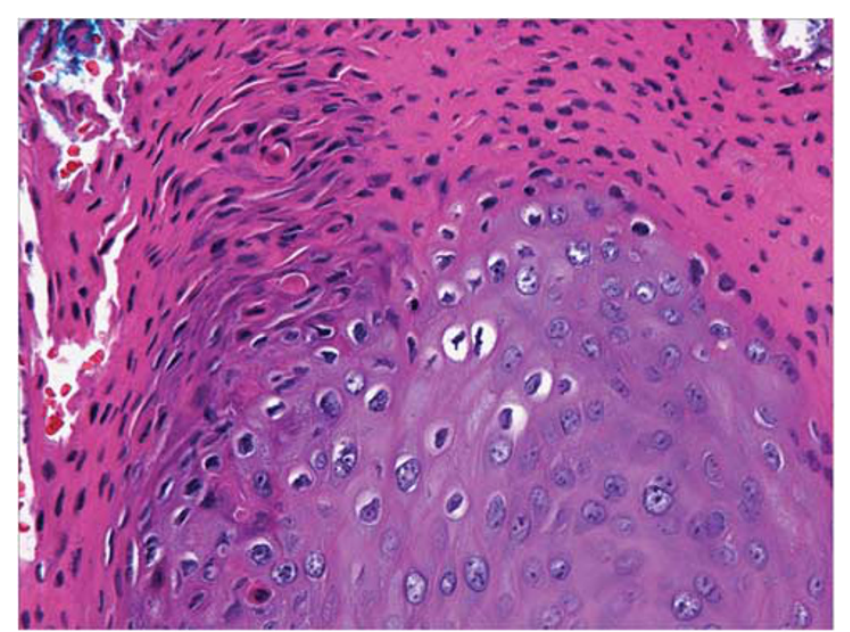

Figure 3 Case no. 3: koilocytes and a few apoptotic cells (hematoxylin and eosin, magnification $\times 400$ ).

the excretory salivary ducts by dysplasia at the time of biopsy (Figure 6a) and subsequently developed an invasive squamous cell carcinoma, 25 months after the original biopsy (Figures 6b-d). One of three cases with negative margins developed three subsequent recurrences (case no. 14). An additional patient with HPV-associated dysplasia (case no.20) was associated with an invasive squamous cell carcinoma at the time of biopsy, but further followup was not available. Eight of the 12 patients with follow-up (67\%) showed no evidence of disease.

Both infiltrating squamous cell carcinomas exhibited variable keratin production. Case no. 8 was a conventional infiltrative and keratinizing squamous cell carcinoma. Case no.20 (from the tongue, floor of mouth, and mandibular mucosa) was composed of islands of basaloid cells demonstrating areas of prominent central comedonecrosis, foci of keratinization, and numerous mitotic figures (Figure 7a). In both carcinomas, in situ hybridization studies for high-risk strains of HPV and immunohistochemical evaluation for p16 were strongly positive within the tumor islands as well as in the overlying dysplastic epithelium (Figure 7b).

One further case not included in the analysis presented as a leukoplakia with a papillary surface 
Table 2 Histopathological features and follow-up data

\begin{tabular}{|c|c|c|c|c|c|c|c|c|c|}
\hline Case & Keratin & $\begin{array}{l}\text { Karyo- } \\
\text { rrhexis }\end{array}$ & Apoptosis & $\begin{array}{l}\text { Margin } \\
+ \text { for } \\
\text { dysplasia }\end{array}$ & $\begin{array}{l}\text { p16 } \\
\text { stain }\end{array}$ & $\begin{array}{l}\text { p16 } \\
\text { border* }\end{array}$ & $\begin{array}{l}\text { ISH } \\
\text { high }\end{array}$ & $\begin{array}{l}\text { ISH } \\
\text { low }\end{array}$ & Follow-up \\
\hline 1 & Para + Ortho & + & + & + & 3 & + & 1 & 0 & 46 months-NED \\
\hline 2 & Para & + & + & - & 3 & + & 3 & 0 & $\begin{array}{l}\text { Recurrent at presentation. } \\
\text { No further follow-up }\end{array}$ \\
\hline 3 & Para & + & + & + & TD & $\mathrm{TD}$ & 3 & 0 & 39 months-NED \\
\hline 4 & Para + Ortho & + & + & + & 3 & + & 1 & 0 & 12 months-NED \\
\hline 5 & Para + Ortho & + & + & + & 3 & + & 3 & 0 & 3 months-NED \\
\hline 6 & Para & + & + & + & 3 & + & 2 & 0 & 19 months-NED \\
\hline 7 & Ortho & + & + & + & 3 & + & 2 & 0 & 1 month—NED \\
\hline 8 & Para & + & + & + & 3 & + & 3 & 0 & 25 months-SCCA \\
\hline 9 & Para & + & + & + & 3 & + & 3 & 0 & 2 months-NED \\
\hline 10 & Ortho & + & + & + & 3 & + & 1 & 0 & 2 months-NED \\
\hline 11 & Para & + & + & + & 3 & + & 2 & 0 & Excision at 2 months-lost to follow-up \\
\hline 12 & Para & + & + & + & 3 & + & 1 & 0 & No further follow-up \\
\hline 13 & Para + Ortho & + & + & + & 3 & + & 1 & 0 & 4 months-residual disease \\
\hline 14 & Para + Ortho & + & + & - & 3 & + & 2 & 0 & 5 months-three recurrences \\
\hline 15 & Ortho & + & + & + & 3 & + & 2 & 0 & $\begin{array}{l}\text { Excision at } 2 \text { months-no further } \\
\text { follow-up }\end{array}$ \\
\hline 16 & Para & + & + & - & 3 & + & 3 & 0 & No further follow-up \\
\hline 17 & Para & + & + & + & 3 & + & 3 & 0 & No further follow-up \\
\hline 18 & Para + Ortho & + & + & + & 3 & + & 3 & 0 & 18 months-residual disease \\
\hline 19 & Para & + & + & + & 3 & + & 3 & 0 & $\begin{array}{l}\text { Excision at } 3 \text { months-no further } \\
\text { follow-up }\end{array}$ \\
\hline 20 & Para & + & + & + & 3 & + & 3 & 0 & $\begin{array}{l}\text { Carcinoma at initial biopsy-no further } \\
\text { follow-up }\end{array}$ \\
\hline
\end{tabular}

ISH high: in situ hybridization studies for high risk strains of HPV; ISH low: in situ hybridization studies for low risk strains of HPV; NED: no evidence of disease; p16 border*: + refers to a sharp demarcation between p16-positive area and adjacent non-dysplastic epithelium; SCCA: squamous cell carcinoma; TD: tissue depleted before p16 stains could be performed.

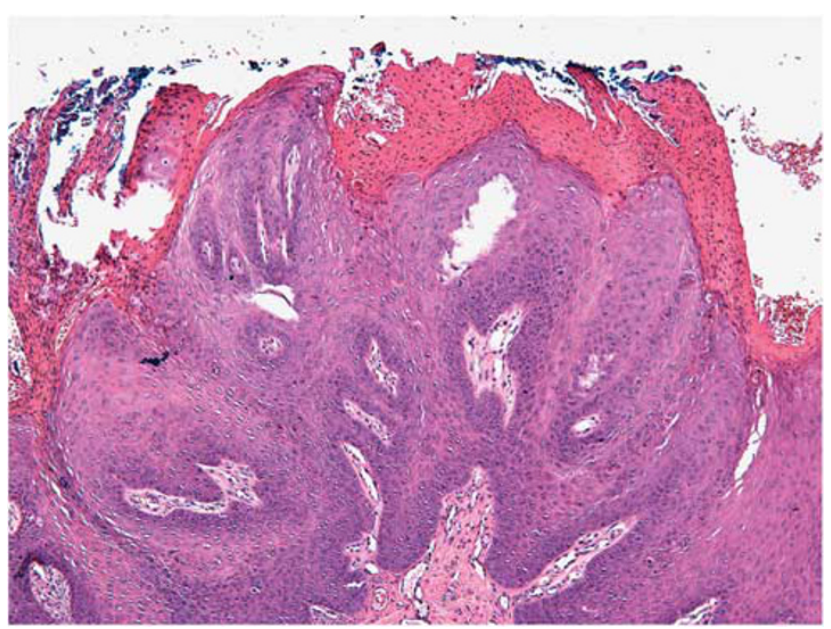

Figure 4 Case no. 3: papillary epithelial hyperplasia (hematoxylin and eosin, magnification $\times 40$ ).

on the floor of mouth of a 39-year-old male. The histopathological features were typical for this condition, but tissue was not available for performing immunohistochemical studies.

\section{Discussion}

The overall prevalence of oral HPV infection in the United States has been estimated at $6.9 \%$ with prevalence of high-risk strains at $3.7 \% .{ }^{15}$ Detection rates for HPV in oral mucosal disease have varied greatly in the literature depending on whether in situ hybridization or PCR is employed. A systematic review performed by Syrjanen et al ${ }^{16}$ determined that HPV DNA was present in many oral lesions, including oral lichen planus, leukoplakias, and oral epithelial dysplasia with odds ratios of 4-5 compared with normal mucosa. HPV detection rates were reported as $0 \%{ }^{17}$ and $80 \%{ }^{18}$ in studies on oral epithelial dysplasia, squamous cell carcinoma, and keratotic lesions performed in the 1990s using in situ hybridization and PCR, respectively; a more recent meta-analysis found a prevalence of $25 \%$ for HPV-16 and/or -18 by in situ hybridization and PCR. ${ }^{12}$ Ha et $a l^{10}$ detected the presence of HPV 16 DNA using real-time quantitative PCR in only 1 of $102(1 \%)$ cases of oral premalignant lesions. Using PCR, D'Costa et al ${ }^{19}$ detected HPV-16 in 34\% of potentially malignant lesions and $31 \%$ of normal mucosa while Bouda et $a l^{20}$ demonstrated high-risk HPV in oral epithelial dysplasia in all the five cases studied. In general, in situ hybridization is a more specific test for detecting the presence of HPV on formalin-fixed material and PCR is overly sensitive. More recently, the use of in situ hybridization for high-risk HPV E6/ E7 ribonucleic acid has shown greater specificity for HPV-driven squamous cell carcinoma. ${ }^{21}$

Very few studies have examined the presence of both high-risk HPV and p16 in oral epithelial dysplasia. Ishibashi et $a l^{22}$ reported that only $7 \%$ 


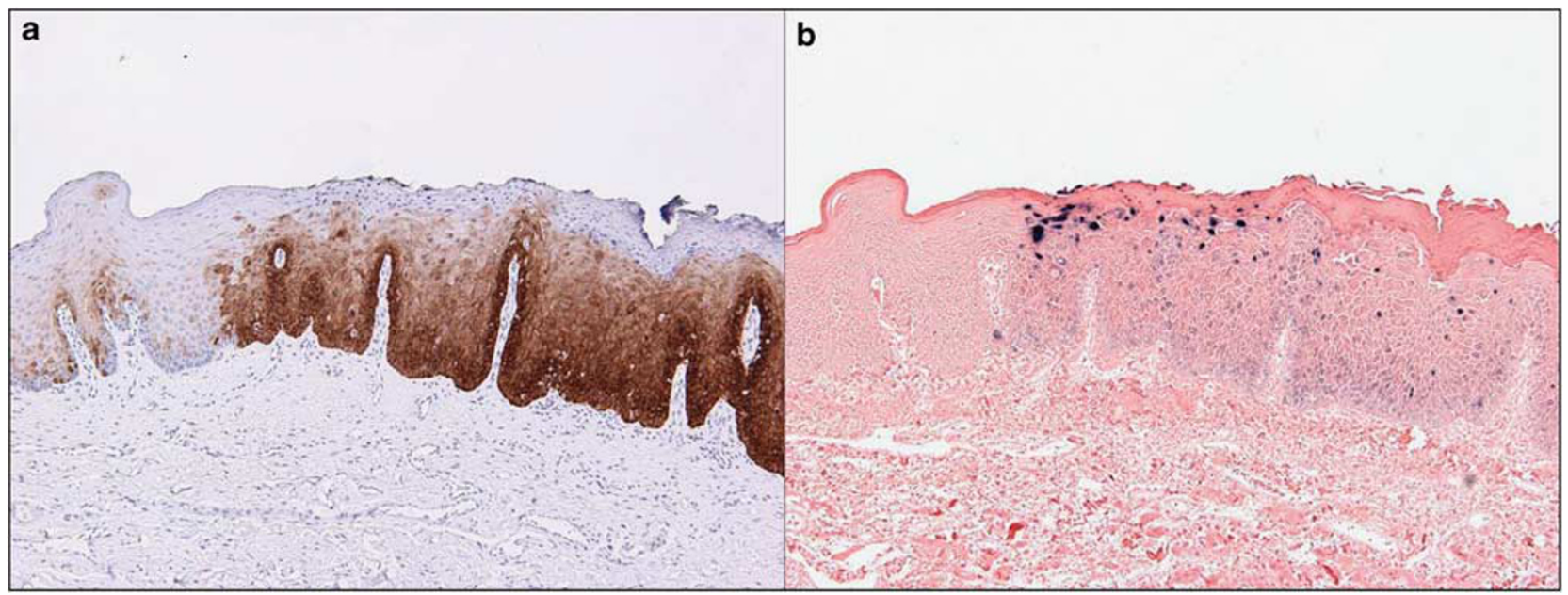

Figure 5 (a) Case no. 16: continuous $3+$ positivity for p16 in a band involving $>90 \%$ of keratinocytes with abrupt transition to nondysplastic mucosa (immunoperoxidase p16, magnification $\times 100$ ); and (b) Case no.16: strong $3+$ positivity for high-risk human papillomavirus in a band with abrupt transition to non-dysplastic mucosa (in situ hybridization, magnification $\times 100$ ).

Table 3 Number of apoptotic cells detected in two high-power $(\times 600)$ fields

\begin{tabular}{lcccc} 
& $\begin{array}{c}\text { HPV-associated oral intra- } \\
\text { epithelial neoplasia }\end{array}$ & & \multicolumn{2}{c}{$\begin{array}{c}\text { Conventional oral } \\
\text { epithelial dysplasia }\end{array}$} \\
\cline { 2 - 3 } \cline { 5 - 5 } Case no. & Field no. 1 & Field no. 2 & Field no. 1 & Field no. 2 \\
\hline 1 & 9 & 9 & 3 & 1 \\
2 & 30 & 33 & 2 & 2 \\
3 & 40 & 38 & 4 & 2 \\
4 & 25 & 28 & 6 & 5 \\
5 & 11 & 14 & 1 & 0 \\
6 & 9 & 9 & 4 & 2 \\
7 & 23 & 16 & 3 & 2 \\
8 & 14 & 14 & 0 & 0 \\
9 & 29 & 33 & 6 & 6 \\
10 & 26 & 22 & 0 & 1 \\
11 & 21 & 23 & 1 & 1 \\
12 & 21 & 23 & 1 & 1 \\
13 & 16 & 13 & 0 & 0 \\
14 & 6 & 6 & 1 & 1 \\
15 & 34 & 17 & 1 & 0 \\
16 & 16 & 14 & 2 & 1 \\
17 & 19 & 19 & 2 & 7 \\
18 & 15 & 16 & 0 & 0 \\
19 & 12 & 9 & 1 & 0 \\
20 & 21 & 20 & 0 & 2 \\
& & & & \\
\hline
\end{tabular}

(4 of 57) of cases of HPV-positive (mostly HPV-31) mild-to-severe oral epithelial dysplasia were also p16 positive, leading them to conclude that overexpression of p16 did not correlate with HPV16 positivity in oral epithelial dysplasia. Angerio et $a^{23}$ demonstrated the expression of p16 in $>90 \%$ of cases of moderate and severe oral epithelial dysplasia (13 of 14 samples); however, only 5 of these 14 cases (36\%) were HPV positive, and of these, $60 \%$ were high-risk subtypes. This underscores that expression of p16 is not exclusive to high-risk HPV activity. ${ }^{24} \mathrm{~A}$ study by Cunningham et $a l^{25}$ showed that 6 out of $41(15 \%)$ moderate-to- severe oral epithelial dysplasias were positive for p16 and HPV DNA, 5 of which were identified as HPV16 positive. Conversely, Buajeeb et a ${ }^{26}$ did not observe any p16 expression in oral epithelial dysplasia. A recent study by Fonseca-Silva et $a 1^{27}$ found a correlation between the presence of HPV-16 and p16 (CDKN2A) methylation in oral epithelial dysplasia.

There are several possible explanations for this discrepancy in HPV and p16 positivity in oral epithelial dysplasia. One of the most important is that previous studies have applied these immunohistochemical studies to any oral epithelial dysplasia. In the present study, we identified a subset of oral epithelial dysplasias with distinct histopathological findings, that harbor high-risk HPV detected by in situ hybridization, and that were p16 positive. The most characteristic feature of the type of dysplasia seen here is the presence of karyorrhexis and apoptosis, with the presence of brightly eosinophilic apoptotic cells throughout the thickness of the epithelium, surrounded by keratinocytes exhibiting conventional dysplastic changes. Although in situ hybridization studies showed the presence of high-risk HPV in all the 20 cases, few typical koilocytes were noted using the strict criteria that cells must not only show peri-nuclear halos but also nuclear enlargement, hyperchromasia, and irregular nuclear outlines. The current cases showed strong cytoplasmic and nuclear positivity for highrisk HPV subtypes and continuous and strong staining for p16 similar to findings observed in HPV-associated cervical intraepithelial neoplasia and HPV-associated oropharyngeal carcinomas.

In 2012, a consensus group co-sponsored by the College of American Pathologists recommended a unified nomenclature for HPV-associated lesions of the lower anogenital tract that included site-specific terminology (eg, cervical intraepithelial neoplasia 


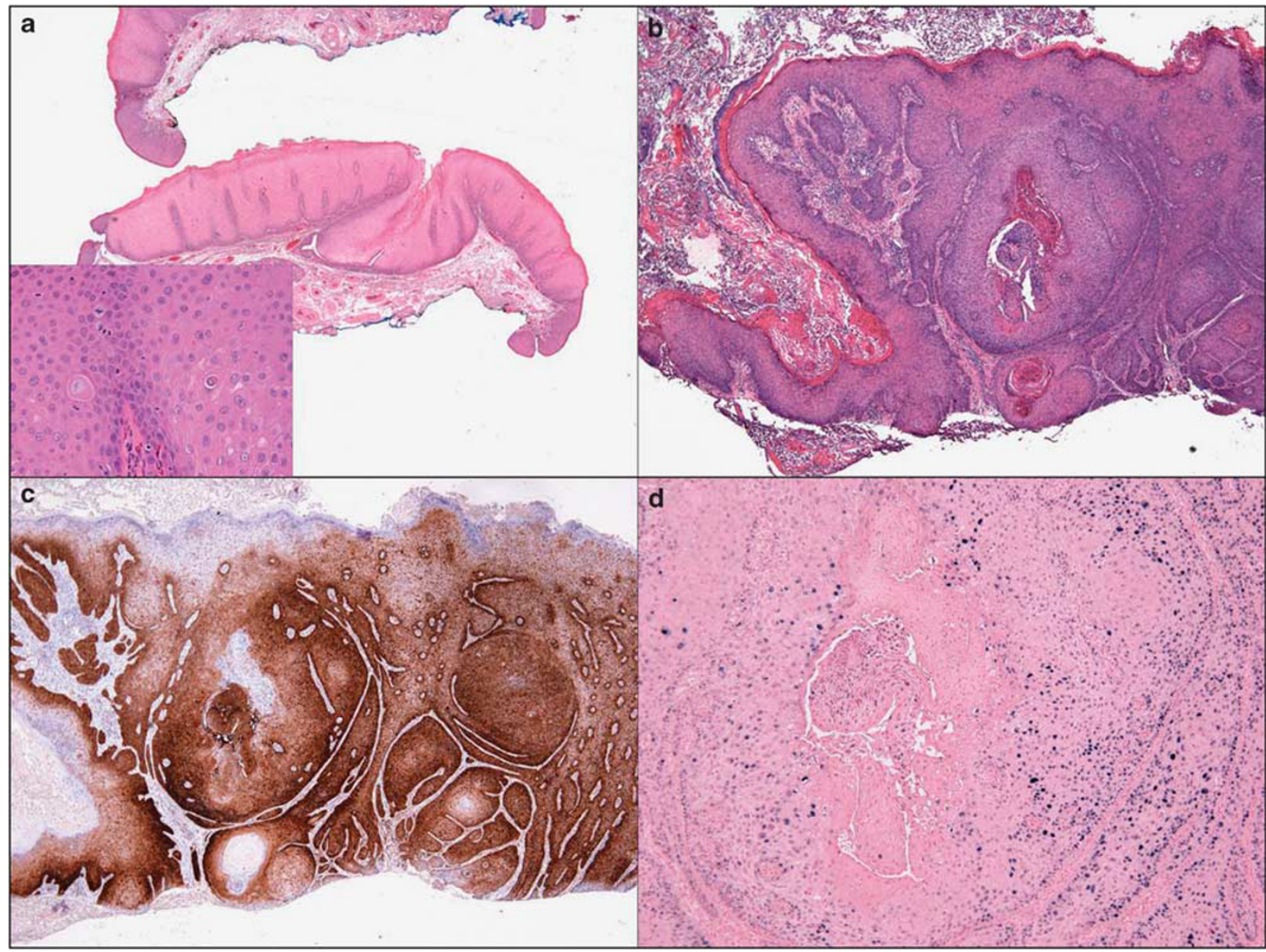

Figure 6 (a) Case no. 8: involvement of excretory salivary duct by dysplastic epithelial cells with karyorrhectic and apoptotic cells (inset) (hematoxylin and eosin, magnification $\times 20$, inset magnification $\times 400$ ); (b) Case no.8: infiltrating squamous cell carcinoma (hematoxylin and eosin, magnification $\times 40$ ); (c) Case no.8: infiltrating squamous cell carcinoma (immunoperoxidase p16, magnification $\times 40$ ); and (d) Case no. 8: infiltrating squamous cell carcinoma (in situ hybridization, magnification $\times 100$ ).

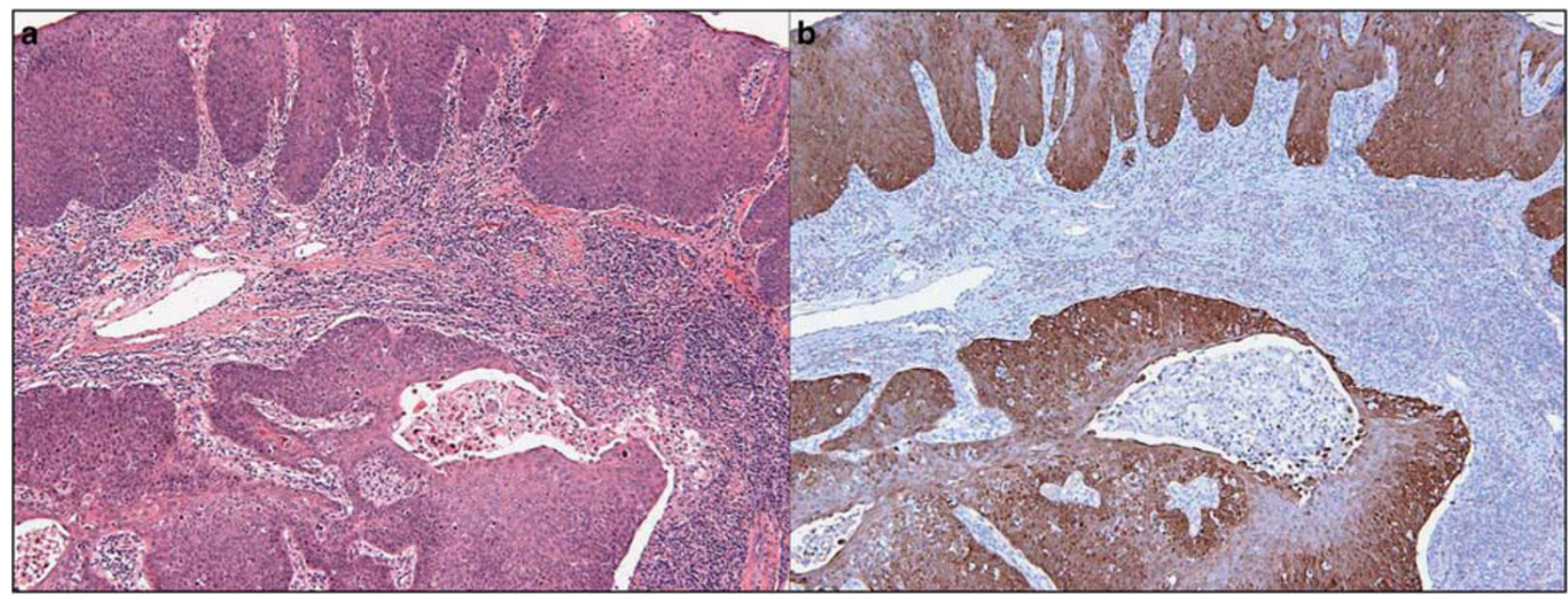

Figure 7 (a) Case no. 20: invasive carcinoma composed of basaloid islands with central comedonecrosis. (hematoxylin and eosin, magnification $\times 100$ ). $($ b) Case no.20: tumor islands showing strong p16 overexpression (immunoperoxidase p16, magnification $\times 40$ ).

for lesions of the cervix, vulvar intraepithelial neoplasia for lesions of the vulva). ${ }^{28}$ The term 'oral intra-epithelial neoplasia (OIN)’ had been proposed by Kuffer and Lombardi in 2002 to classify oral precancerous lesions, and there have been similar efforts since to introduce a two-tiered grading 
system. ${ }^{29,30}$ However, neither the term 'OIN' nor a binary classification system has been universally adopted for oral and/or head and neck precancerous lesions. Nevertheless, all the 20 cases in this evaluation showed involvement of $>2 / 3$ of the epithelium and would therefore be classified as high-grade lesions. At this time, it is unclear whether a low-grade variant of this condition exists. As such, we propose the term 'HPV-associated Oral Intraepithelial Neoplasia' (HPV-OIN) to describe this distinct form of oral epithelial dysplasia for consistency with the nomenclature proposed by Darragh et $a l^{28}$ for HPV-associated lesions of the lower anogenital tract.

All cases on which immunohistochemical studies for p16 were performed showed $3+$ p16 staining in a continuous band similar to that seen in HPV-associated cervical dysplasia and high-risk HPV-associated carcinoma. As such, a 'positive' or 'negative' result is sufficient rather than stratifying into $1+, 2+$, or $3+$ staining patterns. This contrasts with in situ hybridization positivity, which ranged in these cases from $1+$ to $3+$. The significance of this in terms of lesional behavior is unclear, although we note that both cases associated with carcinomas exhibited $3+$ positivity. The sharp demarcation of the in situ hybridization studies for high-risk HPV subtypes in most cases correlated exactly with the presence of the continuous band for p16 as expected. This pattern was noted in the illustrations in the study by Cunningham et $a l^{25}$ The frequency of development of invasive carcinoma if such lesions are incompletely excised is unknown. Among cases with follow-up in this study, 3 out of 11 cases $(27 \%)$ excised with positive margins demonstrated progression of residual disease with 1 developing a carcinoma.

There have been previous reports of oral epithelial dysplasia described as 'koilocytic dysplasia' that were HPV positive. Fornatora et al ${ }^{31}$ reported 31 cases with a male predominance (approximately 5:1) and 7 of 31 patients either positive for HIV or who had engaged in activities putting them at risk for HIV infection.Unlike the current series of cases, several of the lesions were located on the lips, exhibited low-risk strains of HPV, and/or were multi-focal; it is possible that some may have represented oral bowenoid papulosis of the oral cavity, which is rare but exhibits a similar histology. ${ }^{32-34}$ A recently reported case of 'koilocytic dysplasia' showed the same apoptotic changes as noted in this study but was not evaluated for either HPV or p16. ${ }^{35}$

Similar histopathological findings have been noted in Bowen disease (solitary squamous cell carcinoma in situ) and bowenoid papulosis (multiple papules in the genital region), although the degree of apoptosis is not as prominent. Bowen disease of sun-damaged skin may show strong p16 positivity but has a low association with HPV. ${ }^{36}$ On the other hand, bowenoid papulosis is highly associated with high-risk HPV-16 subtypes but p16 overexpression ranges from $43-58 \% ; ;^{37-39}$ some of these lesions progress to invasive squamous cell carcinoma.

Similar cells exhibiting karyorrhexis, although to a lesser degree than in the current cases, have been referred to as 'mitosoid bodies.' They are seen in cases of Heck disease, squamo-papular lesions that consist of multiple papules on the oral mucosa associated with HPV-13, -32 , and $-55 .{ }^{40,41}$ These lesions tend to occur in children and young adults and regress over time. These bodies are also seen in oral warts/condyloma without dysplasia that have been referred to as oral bowenoid lesions. ${ }^{33}$ It is likely that such karyorrhexis is a form of HPVassociated cytopathic effect. However, the progression to fully apoptotic anucleate cells is not usually seen in such large numbers in either Heck disease or bowenoid papulosis, and dysplasia is not present.

One of the two invasive carcinomas (case no. 20) featured a basaloid pattern with areas of prominent comedonecrosis. Although focal areas of keratinization were noted, the features were overall consistent with those of HPV-associated oropharyngeal carcinomas. ${ }^{42-44}$ The other carcinoma was a conventional infiltrative and keratinizing squamous cell carcinoma.

\section{Conclusion}

We report a subset of oral epithelial dysplasia, the majority clinically presenting as oral leukoplakias, that occur mostly in adult men and that are positive for high-risk HPV subtypes and for p16. These present primarily on the ventral tongue or floor of mouth, both considered high-risk sites for oral cancer. We suggest use of the term 'HPV-associated Oral Intraepithelial Neoplasia' for consistency in nomenclature with HPV-associated lesions of the lower anogenital tract. Two patients with follow-up developed invasive carcinoma or recurrence for a total of $17 \%$ of cases with adverse outcomes; an additional patient was diagnosed with an invasive squamous cell carcinoma at the time of biopsy. Further studies may be appropriate to evaluate the behavior and prognosis of this entity.

\section{Addendum}

Since completing preparation of this manuscript, we have seen an additional five cases with identical or nearly identical findings with those of the study. There were three male and two female patients, aged $51,64,67,67$, and 74 years. The specimens were taken from the lateral tongue, buccal mucosa, lower labial mucosa, ventral tongue, and incisive papilla, respectively. All cases demonstrated similar light microscopic findings, including prominent paraker- 
atosis, apoptosis, karyorrhexis, and severe epithelial dysplasia. Each exhibited strong positivity for p16 in a continuous band and positivity for high-risk strains of HPV by in situ hybridization studies. Although follow-up was not available at the time of publication, this brings the total number of cases of HPV-OIN to 25 in this series.

\section{Acknowledgements}

We acknowledge the assistance of Ms. Shannon Stock for her help with the statistical analysis, Dr Christopher Crum, Dr Sadru Kabani, Dr Vikki Noonan, and the following clinicians: Dr Richard Bravman, Hyannis, MA, USA; Dr Claris Chuah, Concord, MA, USA; Dr Craig Cohen, West Lebanon, NH, USA; Dr Brett Denhart, Chicopee, MA, USA; Dr Sotirios Diamantis, Lowell, MA, USA; Dr Martin Elson, Cranston, RI, USA; Dr Douglas Emery, Pawtucket, RI, USA; Dr Michael Gelfman, Lebanon, NH, USA; Dr Michael Jacobsen, South Portland, ME, USA; Dr Paul Kuo, Brookline, MA, USA; Dr John Langston, Falmouth, MA, USA; Dr Killian MacCarthy, Portland, ME, USA; Dr Brandon Meier, South Yarmouth, MA, USA; Dr Laurie Manthos, Worcester, MA, USA; Dr Stephen Pittman, Milford, MA, USA; Dr Xue Yu Shen, Worcester, MA, USA; Dr Robert Stern, Brighton, MA, USA; Dr Bruce Sullivan, Norwood, MA, USA; and Dr Michael Williams, Pittsfield, MA, USA.

\section{Disclosure/conflict of interest}

The authors declare no conflict of interest.

\section{References}

1 Howlader NNA, Krapcho M, Neyman N, et al. SEER Cancer Statistics Review. National Cancer Institute 1975-2008.

2 Shiboski CH, Schmidt BL, Jordan RC. Tongue and tonsil carcinoma: increasing trends in the U.S. population ages 20-44 years. Cancer 2005;103:1843-1849.

3 Patel SC, Carpenter WR, Tyree S, et al. Increasing incidence of oral tongue squamous cell carcinoma in young white women, age 18 to 44 years. J Clin Oncol 2011;29:1488-1494.

4 D’Souza G, Kreimer AR, Viscidi R, et al. Case-control study of human papillomavirus and oropharyngeal cancer. N Engl J Med 2007;356:1944-1956.

5 El-Mofty SK. Human papillomavirus (HPV) related carcinomas of the upper aerodigestive tract. Head Neck Pathol 2007;1:181-185.

6 Chung CH, Gillison ML. Human papillomavirus in head and neck cancer: its role in pathogenesis and clinical implications. Clin Cancer Res 2009;15:6758-6762.

7 Chernock RD, Lewis JS Jr, Zhang Q, et al. Human papillomavirus-positive basaloid squamous cell carcinomas of the upper aerodigestive tract: a distinct clinicopathologic and molecular subtype of basaloid squamous cell carcinoma. Hum Pathol 2010;41: 1016-1023.

8 Chaturvedi AK, Engels EA, Pfeiffer RM, et al. Human papillomavirus and rising oropharyngeal cancer incidence in the United States. J Clin Oncol 2011;29: 4294-4301.

9 Ang KK, Harris J, Wheeler R, et al. Human papillomavirus and survival of patients with oropharyngeal cancer. N Engl J Med 2010;363:24-35.

10 Ha PK, Pai SI, Westra WH, et al. Real-time quantitative PCR demonstrates low prevalence of human papillomavirus type 16 in premalignant and malignant lesions of the oral cavity. Clin Cancer Res 2002;8: 1203-1209.

11 Herrero R, Castellsague X, Pawlita M, et al. Human papillomavirus and oral cancer: the International Agency for Research on Cancer multicenter study. J Natl Cancer Inst 2003;95:1772-1783.

12 Jayaprakash V, Reid M, Hatton E, et al. Human papillomavirus types 16 and 18 in epithelial dysplasia of oral cavity and oropharynx: a meta-analysis, 1985-2010. Oral Oncol 2011;47:1048-1054.

13 Gale N, Pilch BZ, Sidransky D, et al. Epithelial precursor lesions, In: Barnes LEJ, Reichart P, Sidransky D(eds). World Health Organization Classification of Tumours. Pathology and Genetics of Head and Neck Tumours. IARC Press: Lyon, France; 2005, pp 140-143.

14 Warnakulasuriya S, Reibel J, Bouquot J, et al. Oral epithelial dysplasia classification systems: predictive value, utility, weaknesses and scope for improvement. J Oral Pathol Med 2008;37:127-133.

15 Gillison ML, Broutian T, Pickard RK, et al. Prevalence of oral HPV infection in the United States, 2009-2010. JAMA 2012;307:693-703.

16 Syrjanen S, Lodi G, von Bultzingslowen I, et al. Human papillomaviruses in oral carcinoma and oral potentially malignant disorders: a systematic review. Oral Dis 2011;17(Suppl 1):58-72.

17 Zeuss MS, Miller CS, White DK. In situ hybridization analysis of human papillomavirus DNA in oral mucosal lesions. Oral Surg Oral Med Oral Pathol 1991; 71:714-720.

18 Fouret P, Martin F, Flahault A, et al. Human papillomavirus infection in the malignant and premalignant head and neck epithelium. Diagn Mol Pathol 1995;4:122-127.

19 D'Costa J, Saranath D, Dedhia P, et al. Detection of HPV-16 genome in human oral cancers and potentially malignant lesions from India. Oral Oncol 1998;34: 413-420.

20 Bouda M, Gorgoulis VG, Kastrinakis NG, et al. 'High risk' HPV types are frequently detected in potentially malignant and malignant oral lesions, but not in normal oral mucosa. Mod Pathol 2000;13:644-653.

21 Pannone G, Rodolico V, Santoro A, et al. Evaluation of a combined triple method to detect causative HPV in oral and oropharyngeal squamous cell carcinomas: p16 immunohistochemistry, consensus PCR HPV-DNA, and in situ hybridization. Infect Agent Cancer 2012; $7: 4$.

22 Ishibashi M, Kishino M, Sato S, et al. The prevalence of human papillomavirus in oral premalignant lesions and squamous cell carcinoma in comparison to cervical lesions used as a positive control. Int J Clin Oncol 2011;16:646-653.

23 Angiero F, Gatta LB, Seramondi R, et al. Frequency and role of HPV in the progression of epithelial dysplasia to oral cancer. Anticancer Res 2010;30:3435-3440. 
24 Konig F, Krekeler G, Honig JF, et al. Relation between human papillomavirus positivity and p16 expression in head and neck carcinomas-a tissue microarray study. Anticancer Res 2007;27:283-288.

25 Cunningham LL Jr., Pagano GM, Li M, et al. Overexpression of p16INK4 is a reliable marker of human papillomavirus-induced oral high-grade squamous dysplasia. Oral Surg Oral Med Oral Pathol Oral Radiol Endod 2006;102:77-81.

26 Buajeeb W, Poomsawat S, Punyasingh J, et al. Expression of p16 in oral cancer and premalignant lesions. J Oral Pathol Med 2009;38:104-108.

27 Fonseca-Silva T, Farias LC, Cardoso CM, et al. Analysis of p16(CDKN2A) methylation and HPV-16 infection in oral mucosal dysplasia. Pathobiology 2012;79: 94-100.

28 Darragh TM, Colgan TJ, Cox JT, et al. The Lower Anogenital Squamous Terminology Standardization Project for HPV-Associated Lesions: background and consensus recommendations from the College of American Pathologists and the American Society for Colposcopy and Cervical Pathology. Arch Pathol Lab Med 2012;136:1266-1297.

29 Kuffer R, Lombardi T. Premalignant lesions of the oral mucosa. A discussion about the place of oral intraepithelial neoplasia (OIN). Oral Oncol 2002;38: 125-130.

30 Kujan O, Oliver RJ, Khattab A, et al. Evaluation of a new binary system of grading oral epithelial dysplasia for prediction of malignant transformation. Oral Oncol 2006;42:987-993.

31 Fornatora $\mathrm{M}$, Jones AC, Kerpel S, et al. Human papillomavirus-associated oral epithelial dysplasia (koilocytic dysplasia): an entity of unknown biologic potential. Oral Surg Oral Med Oral Pathol Oral Radiol Endod 1996;82:47-56.

32 Kratochvil FJ, Cioffi GA, Auclair PL, et al. Virusassociated dysplasia (bowenoid papulosis?) of the oral cavity. Oral Surg Oral Med Oral Pathol Oral Radiol Endod 1989;68:312-316.

33 Daley T, Birek C, Wysocki GP. Oral bowenoid lesions: differential diagnosis and pathogenetic insights. Oral
Surg Oral Med Oral Pathol Oral Radiol Endod 2000;90:466-473.

34 Rinaggio J, Glick M, Lambert WC. Oral bowenoid papulosis in an HIV-positive male. Oral Surg Oral Med Oral Pathol Oral Radiol Endod 2006;101:328-332.

35 Klingbeil MF, De Lima MD, Gallottini MH, et al. Oral koilocytic dysplasia: long-term clinical control. A case report. Minerva Stomatol 2012;61:288-293.

36 Willman JH, Heinz D, Golitz LE, et al. Correlation of p16 and pRb expression with HPV detection in Bowen's disease. J Cutan Pathol 2006;33:629-633.

37 Auepemkiate S, Thongsuksai P, Boonyaphiphat P. $\mathrm{P} 16$ (INK4A) expression in Bowen's disease and Bowenoid papulosis. J Med Assoc Thai 2006;89:1460-1465.

38 Liu H, Urabe K, Moroi Y, et al. Expression of p16 and hTERT protein is associated with the presence of highrisk human papillomavirus in Bowenoid papulosis. J Cutan Pathol 2006;33:551-558.

39 Wikstrom A, Hedblad MA, Syrjanen S. Penile intraepithelial neoplasia: histopathological evaluation, HPV typing, clinical presentation and treatment. J Eur Acad Dermatol Venereol 2012;26:325-330.

40 Cuberos V, Perez J, Lopez CJ, et al. Molecular and serological evidence of the epidemiological association of HPV 13 with focal epithelial hyperplasia: a casecontrol study. J Clin Virol 2006;37:21-26.

41 Gonzalez LV, Gaviria AM, Sanclemente G, et al. Clinical, histopathological and virological findings in patients with focal epithelial hyperplasia from Colombia. Int J Dermatol 2005;44:274-279.

42 El-Mofty SK, Lu DW. Prevalence of human papillomavirus type 16 DNA in squamous cell carcinoma of the palatine tonsil, and not the oral cavity, in young patients: a distinct clinicopathologic and molecular disease entity. Am J Surg Pathol 2003;27:1463-1470.

43 Lewis JS Jr., Thorstad WL, Chernock RD, et al. p16 positive oropharyngeal squamous cell carcinoma:an entity with a favorable prognosis regardless of tumor HPV status. Am J Surg Pathol 2010;34:1088-1096.

44 Marur S, D’Souza G, Westra WH, et al. HPV-associated head and neck cancer: a virus-related cancer epidemic. Lancet Oncol 2010;11:781-789. 